\title{
Prevalence of Coronary Artery Disease in Japanese Patients With Cerebral Infarction Impact of Metabolic Syndrome and Intracranial Large Artery Atherosclerosis
}

\author{
Atsushi Hoshino, MD*; Takashi Nakamura, MD; Satoko Enomoto, MD*; Hiroyuki Kawahito, MD*; \\ Hiroyuki Kurata, MD; Yoshifumi Nakahara, MD; Toshiharu Ijichi, MD**
}

\begin{abstract}
Background Patients with cerebral infarction have a high prevalence of asymptomatic coronary artery disease (CAD) and other vascular diseases, but there is a lack of such data for Japanese patients, so the present study investigated the prevalence of cardiovascular disease (CVD) in Japanese patients and determined the predictors of CAD.

Methods and Results The study group comprised 104 patients with cerebral infarction who had no history of CVD. All patients underwent coronary computed tomographic angiography, and systematic evaluation was done on the basis of the presence of other vascular diseases, CVD risk markers, and the degree of atherosclerosis. Of the total, 39 patients $(37.5 \%)$ had CAD, $9(8.7 \%)$ had carotid artery stenosis, $9(8.7 \%)$ had peripheral artery disease of the lower limbs, and $3(2.9 \%)$ had atherosclerotic renal artery stenosis. Multiple regression analysis showed that the presence of CAD was independently associated with metabolic syndrome (odds ratio (OR) 5.008, 95\% confidence interval (CI) 1.538-16.309; $\mathrm{p}<0.01$ ) and intracranial large artery atherosclerosis (OR 4.979, 95\% CI 1.633-15.183; $\mathrm{p}<0.01)$.

Conclusion Japanese patients with cerebral infarction have a high prevalence of CVD, especially asymptomatic CAD. Both metabolic syndrome and intracranial large artery atherosclerosis may be potential predictors for identifying patients with cerebral infarction who are at the highest risk of asymptomatic CAD. (Circ J 2008; 72: $404-408)$
\end{abstract}

Key Words: Cerebral infarction; Computed tomography; Coronary artery disease; Magnetic resonance imaging; Metabolic syndrome

$\Delta$ therosclerosis is a widespread disorder involving various arterial territories and it is a progressive disease process. Compared with the general population, patients with cerebral infarction have an increased risk of death, notably from coronary artery disease (CAD)! In addition, patients with cerebral infarction die more frequently from $\mathrm{CAD}$ than from recurrent cerebral infarction or other neurological diseases- ${ }^{2-4}$

There is a racial difference in the sites of prevalence for atherosclerotic lesions. Asian people have been shown to have more severe intracranial vascular lesions, whereas Western people have more severe extracranial lesions ${ }^{5}$ and there is a strong correlation between the extent of coronary atherosclerosis and extracranial carotid atherosclerosis. $6-8$ In Japan, adoption of a Westernized lifestyle has caused an

(Received September 12, 2007; revised manuscript received October 26, 2007; accepted October 30, 2007)

Department of Cardiology, Saiseikai Shiga Hospital, Ritto, *Department of Cardiology, Kyoto Prefectural University of Medicine, Kyoto and **Saiseikai Shiga Hospital, Neurology, Ritto, (present) Ijichi clinic, Kyoto, Japan

Mailing address: Atsushi Hoshino, MD, Department of Cardiology, Kyoto Prefectural University of Medicine, 465 Kajii-cho, KawaramachiHirokoji, Kamigyo-ku, Kyoto 602-8566, Japan. E-mail: a-hoshi@koto. kpu-m.ac.jp

All rights are reserved to the Japanese Circulation Society. For permissions, please e-mail: cj@j-circ.or.jp increase in extracranial carotid artery disease and CAD,, 10 so for patients with cerebral infarction it is important to prevent not only intracranial recurrence but also other cardiovascular events. Screening for CAD could potentially improve prognoses, as several studies of patients with asymptomatic ischemia suggest that medical treatment and revascularization alter prognoses to an extent beyond risk factor reduction!1

The main objective of the present study was to estimate the prevalence of cardiovascular disease (CVD) in Japanese patients hospitalized for cerebral infarction. The secondary objective was to elucidate the predictors of asymptomatic CAD.

\section{Methods}

\section{Study Population}

We investigated 243 consecutive patients who were admitted between May 2005 and March 2007 because of a first cerebral infarction. Diagnosis of cerebral infarction was based on sudden onset of loss of global or focal cerebral function persisting for $>24 \mathrm{~h}$, as well as findings from computed tomography or magnetic resonance imaging. Patients were excluded if they fulfilled 1 or more of the following criteria: (1) history of clinical CVD, (2) atrial fibrillation, (3) age $\geq 80$ years, (4) modified Rankin scale $\geq 4$, (5) dementia, and (6) renal insufficiency (defined as serum 


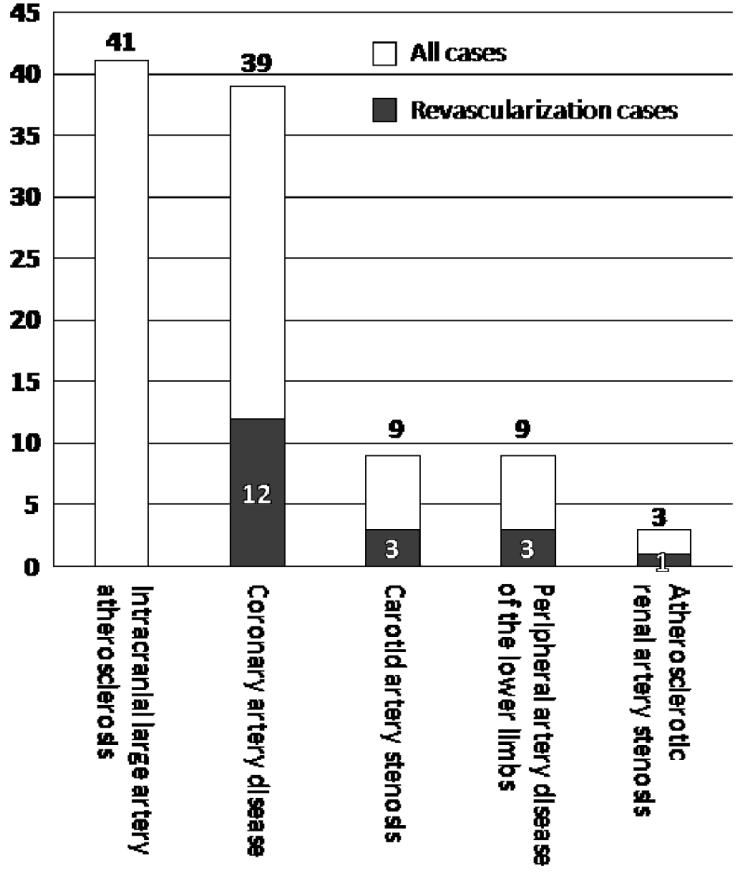

Fig 1. Prevalence of cardiovascular diseases and the number of revascularization cases in 104 Japanese patients with cerebral infarction.

creatinine $\geq 1.6 \mathrm{mg} / \mathrm{dl}$ ). Of the 107 patients enrolled, 3 were excluded because of inadequate images from coronary computed tomographic angiography (CTA). Informed consent was given by all participants and the study protocol was approved by the hospital's ethics committee.

\section{Definitions of Cardiovascular Risk Factors}

The listed cardiovascular risk factors were hypertension, diabetes mellitus, hypercholesterolemia, current smoking, and metabolic syndrome. Blood samples following an overnight fast were obtained from all patients. Hypertension was defined as $\geq 140 / 90 \mathrm{mmHg}$ or current treatment with antihypertensive drugs. Diabetes mellitus was defined as a fasting blood glucose level $\geq 126 \mathrm{mg} / \mathrm{dl}$ and/or a glycosylated hemoglobin level $\geq 6.5 \%$, or treatment with insulin or oral antidiabetic drugs. Hypercholesterolemia was defined as a low-density lipoprotein C level $\geq 140 \mathrm{mg} / \mathrm{dl}$ or current treatment with lipid-lowering drugs. The presence or absence of a smoking history was determined by a standardized selfadministered questionnaire. Metabolic syndrome was defined according to the 2005 definition and diagnostic criteria for Japanese: waist circumference $\geq 85 \mathrm{~cm}$ for men or $\geq 90 \mathrm{~cm}$ for women as an essential component combined with 2 or more of the following components: triglycerides $\geq 150 \mathrm{mg} / \mathrm{dl}$ and/or high-density lipoprotein $\mathrm{C}<40 \mathrm{mg} / \mathrm{dl}$; systolic blood pressure (BP) $\geq 130 \mathrm{mmHg}$ and/or diastolic $\mathrm{BP} \geq 85 \mathrm{mmHg}$; fasting blood glucose $\geq 110 \mathrm{mg} / \mathrm{dl}$.

\section{Ultrasound Examination}

B-mode ultrasound of the carotid arteries was performed using a high-resolution ultrasound machine (HDI5000 ATL, Philips Medical Systems, Andover, MA, USA) and a 5-12-MHz linear array transducer. All examinations were carried out by sonographers who were unaware of the clinical data. The scanning protocol was in accordance with that of Allan et al! ${ }^{2}$
Table 1 Clinical Characteristics of the Study Group

\begin{tabular}{|c|c|}
\hline Age (years) & $65.9 \pm 10.6$ \\
\hline Gender $(M / F)$ & $76 / 28$ \\
\hline$B M I\left(k g / m^{2}\right)$ & $23.8 \pm 3.1$ \\
\hline Waist circumference $(\mathrm{cm})$ & $85.4 \pm 7.6$ \\
\hline \multicolumn{2}{|l|}{ Type of cerebral infarction } \\
\hline Lacunar & $66.4 \%$ \\
\hline Atherothrombotic & $9.6 \%$ \\
\hline Cardioembolic & $16.3 \%$ \\
\hline Other & $7.7 \%$ \\
\hline \multicolumn{2}{|l|}{ Laboratory data } \\
\hline Fasting plasma glucose, $\mathrm{mg} / \mathrm{dl}$ & $123 \pm 49$ \\
\hline LDL-cholesterol, $\mathrm{mg} / \mathrm{dl}$ & $132.3 \pm 34.7$ \\
\hline HDL-cholesterol, $\mathrm{mg} / \mathrm{dl}$ & $48.8 \pm 14.3$ \\
\hline Triglycerides, $\mathrm{mg} / \mathrm{dl}$ & $136.6 \pm 69.4$ \\
\hline Hemoglobin Alc, \% & $6.6 \pm 1.8$ \\
\hline \multicolumn{2}{|l|}{ Cardiovascular risk factors } \\
\hline Hypertension & $51.9 \%$ \\
\hline Hypercholesterolemia & $45.2 \%$ \\
\hline Diabetes mellitus & $36.5 \%$ \\
\hline Smoking & $37.5 \%$ \\
\hline$>2$ risk factors & $23.1 \%$ \\
\hline Metabolic syndrome & $38.5 \%$ \\
\hline
\end{tabular}

BMI, body mass index; LDL, low-density lipoprotein; HDL, high-density lipoprotein.

Measurement of Arterial Pressure and Velocity Indices

The ankle-brachial pressure index (ABI) and brachialankle pulse wave velocity (baPWV) measurements were performed using the oscillometric method. After the patient had rested supine for $>5 \mathrm{~min}$, the baPWV was measured with a volume-plethysmograph (FORM/ABI, Colin Co Ltd, Komaki, Japan) while the subject was in the same position. This instrument simultaneously records the baPWV and the brachial and ankle BPs on the left and right sides, produces an electrocardiogram (ECG), and records the heart sounds. The lowest ABI value and the highest baPWV for the left and right sides were determined. This method has been validated elsewhere ${ }^{13}$

\section{Definitions of CVDs}

CAD was defined as stenosis $\geq 50 \%$ as shown on coronary CTA, during which routine premedication with $\beta$-blockers, 20-60 mg metoprolol for lowering the heart rate, and oral nitroglycerine spray were used. ECG-gated coronary CTA studies were performed with a 8-MDCT scanner (Light Speed Ultra with Xtream, GE Healthcare, Milwaukee, MI, USA). The following imaging and reconstruction parameters were used: detector collimation, $8 \times 1.25 \mathrm{~mm}$; $\mathrm{kVp}, 120$; $\mathrm{mAs}$, 300; pitch, 0.125; rotation time, $0.5 \mathrm{~s}$; slice width, $1.25 \mathrm{~mm}$. We continuously injected $80 \mathrm{ml}$ of non-ionic iodinated contrast material (Iopamiron [iopamidol], $300 \mathrm{mgI} / \mathrm{ml}$, Schering) at a rate of $3.0 \mathrm{ml} / \mathrm{s}$ using a power injector. The postprocessing reformations were performed on an Advantage Workstation 4.2 (GE Healthcare). A cardiologist who was unaware of the clinical data evaluated the coronary CTA images in consensus, using a modified American College of Cardiology/American Heart Association (ACC/AHA) classification that included all segments $2 \mathrm{~mm}$ or greater in diameter belonging to the left main, left anterior descending, left circumflex, and right coronary arteries.

Intracranial large artery atherosclerosis was defined as visual stenosis or irregularities on magnetic resonance angiography (MRA), which was performed using a 1.5-T magnetic resonance system (Intera 1.5T, Philips Medical Systems). We used a 3-dimensional time-of-flight gradient- 
Table 2 Univariate Analysis of CAD and Other Vascular Diseases

\begin{tabular}{|c|c|c|c|}
\hline & $C A D(+)$ & $C A D(-)$ & $p$ value \\
\hline$n$ & 39 & 65 & \\
\hline Intracranial large artery atherosclerosis* & $24 / 34$ & $17 / 57$ & $<0.001$ \\
\hline Other vascular diseases & 8 & 8 & 0.26 \\
\hline PAD of the lower limbs & 4 & 5 & 0.65 \\
\hline Carotid artery stenosis & 5 & 4 & 0.24 \\
\hline ARAS & 2 & 1 & 0.29 \\
\hline
\end{tabular}

*Thirteen patients' data were not obtained.

CAD, coronary artery disease; $P A D$, peripheral artery disease; ARAS, atherosclerotic renal artery stenosis.

Table 3 Univariate Analysis of Clinical Data of Patients With Cerebral Infarction

\begin{tabular}{lccc}
\hline \hline & $C A D(+)$ & $C A D(-)$ & $p$ value \\
\hline$n$ & 39 & 65 & \\
Age $($ years $)$ & $65.8 \pm 7.2$ & $66.0 \pm 12.2$ & 0.90 \\
Gender $(M / F)$ & $31 / 8$ & $45 / 20$ & 0.25 \\
BMI $\left(\mathrm{kg} / \mathrm{m}^{2}\right)$ & $24.0 \pm 2.7$ & $23.6 \pm 3.3$ & 0.60 \\
Waist circumference $(\mathrm{cm})$ & $86.1 \pm 7.6$ & $85.0 \pm 7.7$ & 0.58 \\
Type of cerebral infarction & & & 0.95 \\
Lacunar & $69.2 \%$ & $64.6 \%$ & \\
Atherothrombotic & $7.7 \%$ & $10.8 \%$ & \\
Cardioembolic & $15.4 \%$ & $16.9 \%$ & \\
Other & $7.7 \%$ & $7.7 \%$ & 0.92 \\
Cardiovascular risk factors & & & 0.88 \\
Hypertension & $51.3 \%$ & $52.3 \%$ & 0.016 \\
Hypercholesterolemia & $46.2 \%$ & $44.6 \%$ & 0.008 \\
Diabetes mellitus & $51.3 \%$ & $27.7 \%$ & $<.0001$ \\
Smoking & $53.8 \%$ & $27.7 \%$ & 0.060 \\
2> risk factors & $35.9 \%$ & $15.4 \%$ & 0.053 \\
Metabolic syndrome & $64.1 \%$ & $23.1 \%$ & 0.29 \\
ABI & $1.05 \pm 0.18$ & $1.11 \pm 0.11$ & \\
baPWV & $2,268 \pm 595$ & $2,053 \pm 443$ & $1.46 \pm 0.62$ \\
IMT & $1.59 \pm 0.63$ & & \\
\hline
\end{tabular}

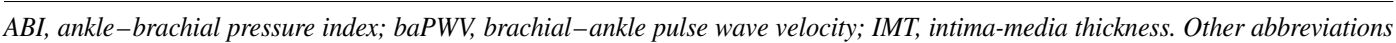
see in Tables 1,2.

echo technique for the intracranial arteries. The intracranial portion of the internal carotid artery, the anterior, middle, posterior cerebral arteries, and basilar artery were evaluated by a radiologist who was unaware of the clinical data.

Carotid artery stenosis was assessed by duplex ultrasonography and defined as stenosis $\geq 50 \%$ as calculated by ECST criteria (the residual luminal diameter divided by the normal diameter of the artery at that level).

Peripheral artery disease (PAD) of the lower limbs was defined as $\mathrm{ABI}<0.9$. Atherosclerotic renal artery stenosis (ARAS) was defined as stenosis $\geq 50 \%$ as demonstrated by CTA or conventional angiography and the additional presence of resistant hypertension. ${ }^{14}$

\section{Statistical Analysis}

All descriptive data are expressed as the mean value \pm SD or the number of patients (percentage). Continuous variables were compared by Student's unpaired t-test. The chi-square test was used for categorical data. To identify predictors of asymptomatic CAD, multivariate logistic regression analyses were used. Univariate variables with $\mathrm{p}<0.20$ were entered into the multivariate logistic models. A value of $\mathrm{p}<$ 0.05 with $95 \%$ confidence interval was considered significant. All statistical analyses were performed using commercially available statistical software (StatView version 5.0, SAS Institute Inc, Cary, NC, USA).

\section{Results}

Prevalence of CVDs and Clinical Features

The prevalence of CVDs and the clinical characteristics for all 104 patients are summarized in Fig 1 and Table 1, respectively. We were not able to obtain the MRA images for 13 patients; 41 patients $(45.1 \%)$ had intracranial large artery atherosclerosis; 39 patients $(37.5 \%)$ had CAD and of them $20(19.2 \%)$ and $12(11.5 \%)$ underwent invasive coronary angiography or percutaneous coronary interventions (PCIs), respectively, because of significant stenosis. Nine patients $(8.7 \%)$ had carotid artery stenosis and $3(2.9 \%)$ underwent carotid artery stenting. Nine patients $(8.7 \%)$ had PAD of the lower limbs and $3(2.9 \%)$ underwent revascularization ( 2 by percutaneous transluminal angioplasty, 1 by operation). Three patients $(2.9 \%)$ had ARAS and 1 (1.0\%) underwent percutaneous transluminal renal angioplasty.

The relationship between asymptomatic CAD and other vascular diseases was analyzed (Table 2). Compared with patients without CAD, those with CAD had a higher prevalence of intracranial large artery atherosclerosis (70.6\% vs $29.8 \%$ ). Between these 2 groups, however, there was no difference in the prevalence of other vascular diseases such as carotid artery stenosis, PAD of the lower limbs, or ARAS. Patients with CAD also had a higher incidence of diabetes mellitus (51.3 vs $27.7 \%$ ), smoking (53.8 vs $27.7 \%$ ), the presence of $>2$ risk factors ( $35.9 \%$ vs $15.4 \%$ ), and metabolic syndrome (64.1 vs $23.1 \%$ ). Intima-media thickness (IMT) and pulse wave velocity values were high but not signifi- 
Table 4 Multivariate Analysis of the Prevalence of Asymptomatic CAD in Patients With Cerebral Infarction

\begin{tabular}{|c|c|c|c|}
\hline & OR & $95 \% C I$ & p value \\
\hline Metabolic syndrome & 5.008 & $1.538-16.309$ & 0.0075 \\
\hline Diabetes mellitus & 0.653 & $0.145-2.947$ & 0.58 \\
\hline Smoking & 2.245 & $0.687-7.336$ & 0.18 \\
\hline $2>$ risk factors & 1.125 & $0.224-5.647$ & 0.89 \\
\hline$A B I$ & 0.079 & $0.001-8.158$ & 0.28 \\
\hline baPWV & 1.000 & $0.999-1.001$ & 0.99 \\
\hline Intracranial large artery atherosclerosis & 4.979 & $1.633-15.183$ & 0.0048 \\
\hline
\end{tabular}

OR, odds ratio; CI, confidence interval. Other abbreviations see in Tables 2,3.

cantly different between groups, as shown in Table 3 .

\section{Predictors for Asymptomatic CAD}

Variables with $\mathrm{p}<0.20$ on univariate logistic regression analysis included diabetes mellitus, smoking, the presence of $>2$ risk factors, metabolic syndrome, $\mathrm{ABI}, \mathrm{baPWV}$, and intracranial large artery atherosclerosis. These factors were then entered into the multivariate logistic model, which showed that metabolic syndrome and intracranial large artery atherosclerosis were independent predictors of asymptomatic CAD in patients with cerebral infarction (Table 4).

\section{Discussion}

There are no previous reports regarding Japanese patients with cerebral infarction or their evaluation by coronary CTA and the present study showed that $37.5 \%$ (39 of 104) of Japanese patients with cerebral infarction had asymptomatic CAD. Small studies have suggested that $23-58 \%$ of stroke patients without clinical CAD may have asymptomatic myocardial ischemia, as determined by exercise ECG or stress myocardial scintigraphy, ${ }^{15-18}$ but Japanese people are considered to have CAD less frequently than Western people $!^{19}$ However, our study showed a similar frequency to other studies of Western populations and although the high incidence may be partially attributed to a CAD definition of $\geq 50 \%$ stenosis, rather than $\geq 75 \%$, we can say that Japanese patients with cerebral infarction have as high a risk of asymptomatic CAD as Western patients.

Multivariate analysis showed that metabolic syndrome and intracranial large artery atherosclerosis were independently associated with asymptomatic CAD in patients with cerebral infarction. Metabolic syndrome is a cluster of specific CVD risk factors, including obesity, impaired glucose regulation, dyslipidemia, and hypertension. Its underlying pathophysiology is thought to be related to insulin resistance ${ }^{20}$ Many studies have shown that patients diagnosed with metabolic syndrome have a higher prevalence of $\mathrm{CAD}^{20,21}$ In addition, hypertension, hypercholesterolemia, diabetes mellitus, and smoking have been long known as major cardiovascular risk factors and patients with multiple risk factors have a higher risk of CAD than patients with a single risk factor ${ }^{22}$ The present study showed that metabolic syndrome is a better predictive marker of asymptomatic CAD in patients with cerebral infarction than every major risk factor either individually or in combination.

Atherosclerosis is a systemic disorder in which disease in one vascular bed reflects disease in other vascular beds? 23 Intracranial large artery atherosclerosis ${ }^{24}$ IMT of the common carotid artery,25-27 $\mathrm{ABI},{ }^{13,27-30}$ and baPWV ${ }^{13,31,32}$ have all been reported to be associated with CAD. In the present study, only intracranial large artery atherosclerosis was an independent predictor of asymptomatic CAD in patients with cerebral infarction. Increased IMT and baPWV are common among patients with cerebral infarction, and are therefore not significantly associated with $\mathrm{CAD}$, but may be useful markers of the early stage of CVD! ${ }^{13}$ The ABI value was also not associated with CAD, possibly because the association between the ABI value and CVD is U-shaped and not inversely proportional 33 Additionally, only 9 of the present patients had a low ABI $(<0.9)$, which is generally associated with a much more advanced stage of CVD 34,35

Whether stroke patients should be investigated for asymptomatic CAD remains a matter of debate! Screening for asymptomatic CAD could potentially improve prognoses, 36 because several studies of patients with asymptomatic ischemia suggest that medical therapy ${ }^{37}$ or revascularization ${ }^{1,38-40}$ alter prognoses to an extent beyond risk factor reduction. Noninvasive screening for asymptomatic CAD in all patients with cerebral infarction may not be cost-effective, so it is essential to distinguish high-risk patients who will benefit most from CAD screening. In patients without any previous history of clinical CAD at the time of stroke, however, a meta-analysis was unable to estimate the risk of myocardial infarction and cardiac death ${ }^{11}$ which highlights the urgency of developing a new screening strategy for secondary prevention. Our study results suggest that metabolic syndrome and intracranial large artery atherosclerosis are factors that may help distinguish patients with cerebral infarction who are at a higher risk of asymptomatic CAD.

\section{Study Limitations}

The number of study patients was small, so a large multicenter study is required to confirm the predictors of complicating asymptomatic CAD. The long-term benefits of detecting $\mathrm{CAD}$ in patients with cerebral infarction also cannot be elucidated from this study. A follow-up of a large cohort is required to determine effects on morbidity and mortality.

\section{Conclusion}

The present study showed that $37.5 \%$ of Japanese patients with cerebral infarction and no history of CAD had asymptomatic CAD. From the viewpoint of cost-effectiveness, selective screening based on risk stratification is required. The present study results suggest that metabolic syndrome and intracranial large artery atherosclerosis, as determined by MRA, may be potential markers of patients with cerebral infarction who are at the highest risk for asymptomatic CAD.

\section{References}

1. Adams RJ, Chimowitz MI, Alpert JS, Awad IA, Cerqueria MD, Fayad $\mathrm{P}$, et al. Coronary risk evaluation in patients with transient ischemic attack and ischemic stroke: A scientific statement for health- 
care professionals from the Stroke Council and the Council on Clinical Cardiology of the American Heart Association/American Stroke Association. Circulation 2003; 108: 1278-1290.

2. Toole JF, Yuson CP, Janeway R, Johnston F, Davis C, Cordell AR, et al. Transient ischemic attacks: A prospective study of 225 patients. Neurology 1978; 28: 746-753.

3. Graor RA, Hetzer NR. Management of coexistent carotid artery and coronary artery disease. Stroke 1988; 19: 1441-1444.

4. Hartmann A, Rundek T, Mast H, Paik MC, Boden-Albala B, Mohr JP, et al. Mortality and causes of death after first ischemic stroke: The Northern Manhattan Stroke Study. Neurology 2001; 57: 2000-2005.

5. Nishimaru K, McHenry LC Jr, Toole JF. Cerebral angiographic and clinical differences in carotid system transient ischemic attacks between American Caucasian and Japanese patients. Stroke 1984; 15: $56-59$.

6. Howard G, Ryu JE, Evans GW, McKinney WM, Toole JF, Murros $\mathrm{KE}$, et al. Extracranial carotid atherosclerosis in patients with and without transient ischemic attacks and coronary artery disease. Arteriosclerosis 1990; 10: 714-719.

7. Crouse JR, Harpold GH, Kahl FR, Toole JF, McKinney WM. Evaluation of a scoring system for extracranial carotid atherosclerosis extent with B-mode ultrasound. Stroke 1986; 17: 270-275.

8. Craven TE, Ryu JE, Espeland MA, Kahl FR, McKinney WM, Toole $\mathrm{JF}$, et al. Evaluation of the associations between carotid artery atherosclerosis and coronary artery stenosis: A case-control study. Circulation 1990; 82: 1230-1242.

9. Komachi Y, Tanaka H, Shimamoto T, Handa K, Iida M, Isomura K, et al. A collaborative study of stroke incidence in Japan: 1975-1979. Stroke 1986; 15: 28-36.

10. Shimamoto T, Komachi Y, Inada H, Doi M, Iso H, Sato S, et al. Trends for coronary heart disease and stroke and their risk factors in Japan. Circulation 1989; 79: 503-515.

11. Touzé E, Varenne O, Chatellier G, Peyrard S, Rothwell PM, Mas JL. Risk of myocardial infarction and vascular death after transient ischemic attack and ischemic stroke: A systematic review and metaanalysis. Stroke 2005; 36: $2748-2755$.

12. Allan PL, Mowbray PI, Lee AJ, Fowkes FG. Relationship between carotid intima-media thickness and symptomatic and asymptomatic peripheral arterial disease: The Edinburgh Artery Study. Stroke 1997; 28: 348-353

13. Koji Y, Tomiyama H, Ichihashi H, Nagae T, Tanaka N, Takazawa K, et al. Comparison of ankle-brachial pressure index and pulse wave velocity as markers of the presence of coronary artery disease in subjects with a high risk of atherosclerotic cardiovascular disease. $A m J$ Cardiol 2004; 94: 868-872.

14. Chobanian AV, Bakris GL, Black HR, Cushman WC, Green LA, Izzo JL Jr, et al; National Heart, Lung, and Blood Institute Joint National Committee on Prevention, Detection, Evaluation, and Treatment of High Blood Pressure; National High Blood Pressure Education Program Coordinating Committee. The Seventh Report of the Joint National Committee on Prevention, Detection, Evaluation, and Treatment of High Blood Pressure: The JNC 7 report. JAMA 2003; 21: $2560-2572$

15. Rokey R, Rolak LA, Harati Y, Kutka N, Verani MS. Coronary artery disease in patients with cerebrovascular disease: A prospective study. Ann Neurol 1984; 16: 50-53.

16. Di Pasquale G, Pinelli G, Grazi P, Andreoli A, Corbelli C, Manini $\mathrm{GL}$, et al. Incidence of silent myocardial ischaemia in patients with cerebral ischaemia. Eur Heart J 1988; 9(Suppl N): 104-107.

17. Chimowitz MI, Poole RM, Starling MR, Schwaiger M, Gross MD. Frequency and severity of asymptomatic coronary disease in patients with different causes of stroke. Stroke 1997; 28: 941 -945.

18. Arenillas JF, Candell-Riera J, Romero-Farina G, Molina CA, Chacón $\mathrm{P}$, Aguadé-Bruix S, et al. Silent myocardial ischemia in patients with symptomatic intracranial atherosclerosis: Associated factors. Stroke 2005; 36: $1202-1206$.

19. Tunstall-Pedoe H, Kuulasmaa K, Amouyel P, Arveiler D, Rajakangas AM, Pajak A. Myocardial infarction and coronary deaths in the World Health Organization MONICA Project: Registration procedures, event rates, and case-fatality rates in 38 populations from 21 countries in four continents. Circulation 1994; 90: 583-612

20. Saely CH, Aczel S, Marte T, Langer P, Hoefle G, Drexel H. The metabolic syndrome, insulin resistance, and cardiovascular risk in diabetic and nondiabetic patients. J Clin Endocrinol Metab 2005; 90: 5698-5703.

21. Eberly LE, Prineas R, Cohen JD, Vazquez G, Zhi X, Neaton JD, et al. Metabolic syndrome: Risk factor distribution and 18-year mortality in the multiple risk factor intervention trial. Diabetes Care 2006; 29: $123-130$.
22. Howard BV, Best LG, Galloway JM, Howard WJ, Jones K, Lee ET, et al. Coronary heart disease risk equivalence in diabetes depends on concomitant risk factors. Diabetes Care 2006; 29: 391-397.

23. Bots ML. Carotid intima-media thickness as a surrogate marker for cardiovascular disease in intervention studies. Curr Med Res Opin 2006; 22: 2181-2190.

24. Uekita K, Hasebe N, Funayama N, Aoyama H, Kuroda K, Aizawa H, et al. Cervical and intracranial atherosclerosis and silent brain infarction in Japanese patients with coronary artery disease. Cerebrovasc Dis 2003; 16: 61-68.

25. Mattace-Raso F, van Popele NM, Schalekamp MA, van der Cammen TJ. Intima-media thickness of the common carotid arteries is related to coronary atherosclerosis and left ventricular hypertrophy in older adults. Angiology 2002; 53: 569-574.

26. Sun K, Takasu J, Yamamoto R, Yokoyama K, Taguchi R, Itani Y, et al. Assessment of aortic atherosclerosis and carotid atherosclerosis in coronary artery disease. Jpn Circ J 2000; 64: 745-749.

27. Papamichael CM, Lekakis JP, Stamatelopoulos KS, Papaioannou TG, Alevizaki MK, Cimponeriu AT, et al. Ankle-brachial index as a predictor of the extent of coronary atherosclerosis and cardiovascular events in patients with coronary artery disease. Am J Cardiol 2000; 86: $615-618$.

28. Igarashi $\mathrm{Y}$, Chikamori T, Tomiyama $\mathrm{H}$, Usui $\mathrm{Y}$, Hida S, Tanaka H, et al. Diagnostic value of simultaneous brachial and ankle blood pressure measurements for the extent and severity of coronary artery disease as assessed by myocardial perfusion imaging. Circ J 2005; 69: $237-242$.

29. Li J, Luo Y, Xu Y, Yang J, Zheng L, Hasimu B, et al. Risk factors of peripheral arterial disease and relationship between low anklebrachial index and mortality from all-cause and cardiovascular disease in Chinese patients with type 2 diabetes. Circ J 2007; 71: 377-381.

30. Chang ST, Chen CL, Chu CM, Lin PC, Chung CM, Hsu JT, et al. Ankle-arm index is a useful test for clinical practice in outpatients with suspected coronary artery disease. Circ J 2006; 70: 686-690.

31. Imanishi R, Seto S, Toda G, Yoshida M, Ohtsuru A, Koide Y, et al. High brachial-ankle pulse wave velocity is an independent predictor of the presence of coronary artery disease in men. Hypertens Res 2004; 27: 71-78.

32. Park SM, Seo HS, Lim HE, Shin SH, Park CG, Oh DJ, et al. Assessment of arterial stiffness index as a clinical parameter for atherosclerotic coronary artery disease. Circ J 2005; 69: 1218-1222.

33. Resnick HE, Lindsay RS, McDermott MM, Devereux RB, Jones KL, Fabsitz RR, et al. Relationship of high and low ankle brachial index to all-cause and cardiovascular disease mortality: The Strong Heart Study. Circulation 2004; 109: 733-739.

34. Sukhija R, Aronow WS, Yalamanchili K, Peterson SJ, Frishman WH, Babu S. Association of ankle-brachial index with severity of angiographic coronary artery disease in patients with peripheral arterial disease and coronary artery disease. Cardiology 2005; 103: 158-160.

35. Su HM, Voon WC, Lin TH, Lee KT, Chu CS, Lee MY, et al. Anklebrachial pressure index measured using an automated oscillometric method as a predictor of the severity of coronary atherosclerosis in patients with coronary artery disease. Kaohsiung J Med Sci 2004; 20: $268-272$.

36. Faglia E, Manuela M, Antonella Q, Michela G, Vincenzo C, Maurizio $\mathrm{C}$, et al. Risk reduction of cardiac events by screening of unknown asymptomatic coronary artery disease in subjects with type 2 diabetes mellitus at high cardiovascular risk: An open-label randomized pilot study. Am Heart J 2005; 149: e1 -e6.

37. Pepine CJ, Cohn PF, Deedwania PC, Gibson RS, Handberg E, Hill $\mathrm{JA}$, et al. Effects of treatment on outcome in mildly symptomatic patients with ischemia during daily life: The Atenolol Silent Ischemia Study (ASIST). Circulation 1994; 90: 762-768.

38. Rogers WJ, Bourassa MG, Andrews TC, Bertolet BD, Blumenthal RS, Chaitman BR, et al. Asymptomatic Cardiac Ischemia Pilot (ACIP) study: Outcome at 1 year for patients with asymptomatic cardiac ischemia randomized to medical therapy or revascularization: The ACIP Investigators. J Am Coll Cardiol 1995; 26: 594-605.

39. Eagle KA, Guyton RA, Davidoff R, Ewy GA, Fonger J, Gardner TJ, et al. ACC/AHA guidelines for coronary artery bypass graft surgery: Executive summary and recommendations: A report of the American College of Cardiology/American Heart Association Task Force on Practice Guidelines (Committee to revise the 1991 guidelines for coronary artery bypass graft surgery). Circulation 1999; 100: 1464-1480.

40. Erne P, Schoenenberger AW, Burckhardt D, Zuber M, Kiowski W, Buser PT, et al. Effects of percutaneous coronary interventions in silent ischemia after myocardial infarction: The SWISSI II randomized controlled trial. JAMA 2007; 297: 1985-1991. 